DOI: http://dx.doi.org/10.5007/1980-3532.2015n14p12

\title{
A escrita sociológica e as temáticas dos livros coletâneas: debates contínuos e descontínuos ${ }^{1}$
}

\author{
The sociological writing and the books' themes collections: discussions \\ continuous and discontinuous
}

\author{
Lígia Wilhelms Eras \\ Doutora em Sociologia pela UFPR. \\ Professora de Sociologia (IFSC)/Campus Xanxerê. \\ ligiaweras@hotmail.com
}

\begin{abstract}
Resumo: O artigo apresenta um debate sobre o Ensino de Sociologia na Educação Básica na identificação das principais temáticas localizadas nos livros coletâneas (2008-2013), em múltiplas metodologias de pesquisa (bibliográfica temática e teórica, histórica, prosopográfica e de análise crítica de conteúdos) predominando na composição do artigo, a análise de conteúdos. O que prevalece no cenário como um todo é um movimento de descontinuidades, quanto à disposição de incorporar uma maior circulação institucional das ideias das experiências de ensino situadas em eventos acadêmicos, projetos de fomento a investigação e iniciação à docência e a uma prévia superação do registro imediato de experiências. Porém, as continuidades ainda se revelam em produções com baixa tiragens e a uma lacuna no avanço de um maior dialogismo entre a produção dos capítulos, edições, inter-obras e as apostas nos inventos teórico-didáticos específicos da subárea.
\end{abstract}

Palavras-Chave: Livros Coletâneas; Temáticas, Análise de Conteúdos.

Abstract: This paper presents the discussion on the Teaching of Sociology in the Basic Education in the identification of the main themes located in books collection (2008-2013), in multiple research methodologies (thematic and theoretical literature, historical, prosopographical and critical content analysis) where content analysis predominates in this article composition. What prevails in the scene as a whole is a movement of discontinuities, as the availability to incorporate greater institutional flow of ideas, educational experiences placed in academic events, development projects to research and introduction to the teaching process and to a preview of immediate registry experiences' overcoming. However, the continuities still show productions with low print runs and a gap to develop a larger dialogism between the production of the chapters, issues, inter-works and bets in the specific theoretical and educational subarea' inventions.

Keywords: Books Gleanings; Thematic, Content Analysis.

Originais recebidos em: 21/03/2016

Aceito para publicação em: 27/06/2016

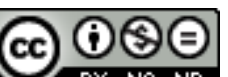

Vedada a criação de obras derivadas 3.0 Unported License.

\footnotetext{
${ }^{1} \mathrm{O}$ artigo é uma síntese das discussões apresentadas no GT de Ensino de Sociologia durante o $17^{\circ}$ Congresso Brasileiro
} de Sociologia, realizado na UFRGS, Porto Alegre, 20 a 23 de julho de 2015. 
As agendas temáticas presentes nos Livros Coletâneas são um reflexo direto das práticas interlocutivas, que resumidas, apresentam-se em duas orientações específicas, contexto $\boldsymbol{e}$ experiência, "como lugar de criação, problematização, prática, diagnóstico e intervenção, ingredientes que retroalimentam as práticas e as teorizações em que o debate poderá orientar novas agendas de discussão, demonstram que é um momento muito oportuno de valorização desses espaços, que é ao mesmo tempo lúdico e teórico" (ERAS e FEIJÓ, 2013).

Destaca-se, no que diz respeito à materialização do discurso, que entre algumas características presentes no nível textual dessas obras coletâneas sobre o Ensino de Sociologia na Educação Básica, analisadas no recorte cronológico de 2008 a $2013^{2}$ estão o predomínio: a) de uma identidade e uma linguagem sociológica; b) um plano normativo-jurídico de abordagem; c) uma apropriação de linguagem pedagógica; d) e, especialmente, uma construção rodeada pelo estilo de metalinguagem ou linguagem autorreferenciada de si mesmos como cientistas sociais-professores.

Observa-se que há um grande leque de estudos-temas em que é possível identificar doze unidades de conteúdos relevantes à construção dos conhecimentos recentes: 1) Estudos sobre a História do Ensino de Sociologia/Ciências Sociais na educação básica; 2) Estudos e os fundamentos teórico-epistemológicos sobre o Ensino de Sociologia/Ciências Sociais na Educação Básica; 3) Estudos sobre o currículo e o Ensino de Sociologia; 4) Estudos sobre Metodologias e Didáticas do Ensino de Sociologia/Ciências Sociais; 5) Estudos sobre as experiências de Ensino de Sociologia; 6) Estudos sobre as Licenciaturas em Ciências Sociais e a formação de professores; 7) Estudos sobre os livros didáticos do Ensino de Sociologia; 8) Estudos sobre a Sociologia da Juventude e o Ensino de Sociologia; 9) Estudos sobre a Sociologia da Educação Pública/Básica; 10) Estudos sobre as Políticas Públicas de Fomento e o Ensino de Sociologia; 11) Estudos de documentos oficiais e legislação educacional; 12) Coletânea de temários/conteúdos estruturantes do Ensino de Sociologia nos Livros Coletâneas - Sociologias Contemporâneas e/ou Plurais (Trabalho; Violência; Religião; Desigualdades Sociais; Gênero; Questões étnico-raciais; Sociologia da Informação; Meio Ambiente; Direitos Sociais e Humanos; Inclusão).

No mapeamento temático acima destacados estão as seguintes análises críticas de seus conteúdos:

1) É possível imediatamente localizar uma grande concentração de estudos nos temas ligados às experiências de ensino e às morfologias dos cursos de Licenciatura em Ciências Sociais, acompanhando a mesma perspectiva das singuralidades de suas experiências de ensino. Tais estudos revelam a demarcação do sentido da especificidade do subcampo num movimento de

\footnotetext{
${ }^{2}$ No mapeamento de obras coletâneas, no referido período analisado, localizamos 23 livros e, na tese, analisamos 16 coletâneas.
} 
disputa pela legitimidade em produzir conhecimento sociológico sobre a escola e sobre o ensino de Sociologia e as transposições didáticas como cerne operador do subcampo. Seria possível ainda agrupar nesse primeiro quadro de identificação de temas, algumas subtemáticas dispersas nos Livros Coletâneas - Sociologia da Juventude, Sociologia no Ensino Médio e Sociologia da Educação Pública e da Educação Básica, Sociologia do Ensino Fundamental - cujos delineamentos também se concentram nos agentes específicos do subcampo: juventude, Ensino Médio, Educação Básica e suas figurações distintas: escola, metodologias, relação ensino-aprendizagem, identidades socioculturais locais, conflituosidades. Os estudos acompanham uma dinâmica de construção de capítulos pautada na descrição das ações e pequenas aproximações analíticas e teóricas, porém, essencialmente reprodutivas em aspecto prático.

Um segundo agrupamento em destaque é o dos estudos sobre História do Ensino de Sociologia, discussões ligadas aos currículos e mais particularizadas nas didáticas. Apesar de parecer uma área previamente delineada, há ainda muita perspectiva de crescimento do subtema, uma vez que, há uma série de sistematizações a serem desenhadas (história das instituições escolares, estudos da identidade docente, estudos do subcampo do ensino de Sociologia). Os estudos sobre currículos revelam o debate nas construções orquestradas nas políticas estaduais de implantação da disciplina no Ensino Médio, o estudo de Caridá (2012) ${ }^{3}$ por exemplo, se propõe a avançar um pouco mais, ao agrupar as particularidades num indicativo de construção nacional, inclusive, numa perspectiva de política remunerativa. O plano didático é uma preocupação precisa do subcampo e onde não se pode descuidar do cultivo de novos estudos com maior acuidade e objetividade analítica, justo porque, é o locus ligado à categoria das experiências, "o lugar de criação, problematização, prática, diagnóstico e intervenção" (ERAS e FEIJÓ, 2013, p. 57), em que se poderá revelar ingredientes inovadores de construção de novas práticas e metodologias de ensino e de agendas-temas ao subcampo. Portanto, nota-se que esse segundo subgrupo ainda reúne o elemento do vir a ser, do que vale a pena insistir numa imaginação sociológica atenta aos seus possíveis desdobramentos e contribuições inovadoras ao campo.

Os três agrupamentos sequenciais revelam os lugares lacunares do subcampo com baixa produtividade dos temas em questão:

3) Poucos capítulos foram dedicados aos estudos dos documentos oficiais e da legislação educacional. Neste segmento, segue a possibilidade de ousar investir em propostas de reflexão sobre as metodologias de ensino de Ciências Sociais adaptadas à sala de aula e para a realidade dos jovens estudantes do Ensino Médio. A proposta do exercício considera que se alie o conhecimento

\footnotetext{
${ }^{3}$ CARIDÁ, Ana Carolina Bordini Brabo. O currículo de Sociologia no Ensino Médio. In: SOUZA PONTES, Fernando. Sociologia: conhecimento e Ensino. Florianópolis: Editora em Debate, 2012.
} 
das diferentes historicidades e o processo de produção dos marcos legais da disciplina, não apenas como um mero conhecimento do campo jurídico de sua constituição, mas naquilo que retroalimenta o debate e as práticas de ensino numa reflexão que aproxime o campo legal e o escolar.

4) Apesar do grande número de capítulos ligados aos estudos de políticas públicas educacionais, há que se esclarecer que ainda estão concentrados em poucos livros coletâneas, no espaço temporal de recorte de nosso estudo, como no caso de PIBID: Memórias de iniciação à docência (2013). A receptividade desses estudos é a grande promessa dos novos rumos da subárea, inter-relacionando para além das experiências pontuais desse frutífero locus de trabalho na formação dos futuros docentes, há que se desenvolver as discussões em torno do sentido do investimento público e sua intervenção numa abrangência mais ampla sobre a história da educação brasileira; abordar a natureza dos programas recentemente presentes na circulação das ideias educacionais em suas particularidades; acentuar a visibilidade dos temas ligados à Licenciatura estendidos para o espaço das pós-graduações, novas linhas e dinâmicas de grupos de ensino e de pesquisas, além de descrever e sistematizar a perspectiva dos quadros de docentes formados nesta dinâmica dos novos fomentos educacionais.

$\mathrm{Na}$ análise das trajetórias dos autores dos Livros Coletâneas alocados em doze diferentes $^{4}$ orientações nas políticas educacionais. Portanto, aguardando futuras sistematizações e materializações no formato de Livros Coletâneas ou em outras produções pedagógico-científicas e suas inovações no subcampo do Ensino de Ciências Sociais/Sociologia na Educação Básica.

5) Os estudos categorizados como Sociologias Contemporâneas e/ou Sociologias Plurais também são perspectivas interessantes ao crescimento do subcampo no aguardo de novas explorações e ousadias sociológicas; até porque auxiliam na reflexão sobre as dinâmicas da sociabilidade atual, cujos espaços/atuações são vivenciados por diferentes agentes ligados à subárea (estudantes, licenciandos, autores e entre outros). Além da existência de poucos capítulos dedicados a essa perspectiva de abordagem sociológica do ensino de Sociologia, estão localizadas em poucos livros, como é o exemplo mais detido de Coleção Explorando o Ensino - Sociologia (2010) no exercício de suas transposições didáticas. Um novo encaminhamento visualizado é a produção de livros coletâneas num modelo temático, que vislumbra um programa editorial que faz as

\footnotetext{
${ }^{4}$ Os programas de fomento citados na coleta de dados durante a entrevista aos autores dos livros coletâneas estão: a) Programa Institucional de Bolsa de Iniciação à Docência - PIBID; b) Programa de Consolidação das Licenciaturas PRODOCÊNCIA; c) Projeto de Ensino e Iniciação Científica - PIBIC; d) Programa Novos Talentos em Ciências Humanas; e) Programação de Apoio de Laboratórios Interdisciplinares de formação de educadores - LIFE; f) Programa Observatório da Educação - OBEDUC; g) Projeto Tutorial Pedagógico; h) Projeto Práxis Licenciatura; i) Programa de Bolsas de Licenciatura - PROLICEN; j) Plano Nacional de Formação de Professores de Educação Básica - PARFOR; k) Educação Tutorial - PET; 1) Formação Continuada de Professores - FORPROF. Alguns desses programas estão credenciados por uma política pública nacional mediada pela CAPES e outras são programas em iniciativas e arranjos locais- institucionais das universidades e suas licenciaturas.
} 
intertextualidades se aproximarem e "conversarem" de modo mais encadeado e com maior organicidade e aprofundamento dos temas elegidos. Podemos citar os livros coletâneas, Inclusão: debates em diferentes contextos (2013) e PIBID: memórias de iniciação à docência (2013) nessa perspectiva de realização e materialização bibliográfica. Além disso, explorar os temas contemporâneos e plurais abre margem para um diálogo mais dinâmico com as próprias Ciências Sociais, seus inúmeros grupos de trabalho em eventos acadêmicos e na prática de ensino/ciência cotidiana, em que a educação e o ensino podem ser essa interface de encontros, inclusive num sentido interdisciplinar com outras ciências.

6) Um agrupamento muito particular são os estudos categorizados como fundamentos teórico-epistemológicos sobre o Ensino de Sociologia/Ciências Sociais na Educação Básica. O número de capítulos dedicados ao tema são restritos, contudo ao avaliar as noções de aporte teórico que prevalecem nesta área de estudo, observa-se que há uma aguda lacuna em termos de formação de um cânone, naquilo que se refira a um conjunto de regras, referência clássica ou modelo, de teorias constituídas sobre o Ensino de Sociologia na Educação Básica, apesar da expressiva quantidade de capítulos de livros. Há que se considerar que, apesar do caráter recente das mudanças em torno desta área, percebe-se, que ao mesmo tempo, existe a potencialidade do conhecimento e, se houver organicidade no processo de sua apropriação, quanto à tradição teórica e metodológica das Ciências Sociais, isso será transferido ao ensino; justo porque, o grande conjunto dos textos comportam produções ligadas à agenda temática da divulgação e difusão dos conhecimentos como resultados de práticas de ensino e de pesquisas sobre o Ensino de Sociologia na Educação Básica, as quais operam noções muito importantes ao campo, a noção de experiência e de prática, condicionadas por uma situação ou um saber local.

Consta que, nos Livros Coletâneas esse exercício está especialmente presente em cinco obras na abrangência dos volumes dispostos nesta análise. Os referidos textos/capítulos destes livros foram produzidos em sua maioria por agentes ligados à formação de professores das Ciências Sociais, situados em universidades públicas e intimamente ligados às disciplinas de Metodologia do Ensino de Ciências Sociais e/ou Didática de Ensino das Ciências Sociais: 1) Sociologia vai à escola: história ensino e docência (2009); 2) Sociologia na sala de aula: reflexões e experiências docentes no Estado do Rio de Janeiro (2012); 3) Dilemas e perspectivas da Sociologia na Educação Básica (2012); 3) Ensino de Sociologia: desafios teóricos pedagógicos para as Ciências Sociais (2013); 4) Sociologia e juventude no Ensino Médio: formação, PIBID e outras experiências (2013). O quadro disposto na sessão de apêndices deste artigo, ilustra o estado da arte, e uma classificação de orientação dessas reflexões, incorporadas ao primeiro grupo, as teorias sociológicas-pedagógicas; no segundo grupo, as teorias sociológicas; no terceiro agrupamento, o 
tema mais polêmico, a teoria sociológica e o ensino como intervenção sociológica (uma sociologia pública); e, no quarto e último, orientações metodológicas e epistêmicas.

I. Teorias Sociológicas-Pedagógicas: Percebe-se que as reflexões presentes nos Livros Coletâneas são pertinentes e originais, uma vez que, revelam a postura do pensador das Ciências Sociais, que se preocupa com as relações de ensino e a tarefa intelectual-docente de elaborar exercícios teórico-pedagógicos e suas adequações a uma composição de fundamentos e metodologias voltados à Educação Básica. É, portanto, o ponto alto de localização das tensões no campo, a busca de legitimação em estabelecer suas bases, cujos pontos de vista são ainda muito dispersos e divergentes. Os autores utilizam um discurso perito proveniente das bases didáticas, em que a conexão se mantém entre o Ensino Superior e a realidade pedagógica das escolas.

II. Teorias Sociológicas e Ensino: O exercício que se intenciona realizar nestas análises consideram a iniciativa de mobilizar o debate nas teorias sociológicas específicas e no estabelecimento das interfaces ao ensino de Sociologia. A propósito, todas as reflexões conduzem à síntese das perspectivas: para que serve a Sociologia? A questão movimenta o debate, dado que a obrigatoriedade jurídico-legal é permanentemente inquirida e cuja legitimidade deste subcampo de estudos terá abrangência de possíveis renovações; e, além disso, maior participação e produção de crenças, quando os aportes teóricos puderem oferecer o capital simbólico de trânsito reconhecido aos dois campos. Cita-se, neste contexto que, de um lado exige-se uma tomada de posição diante das reflexões e, de outro, uma postura diante das opções didáticas e a operar a formação do cientista social-professor nestas elaborações didáticas.

III. Teoria Sociológica e Intervenção Social: Tal discussão, associada à realidade do ensino, abre ainda um precedente à reflexão acerca das teorias e das práticas da Sociologia num papel de intervenção social. Os pressupostos do debate partem de Ciência e Política: duas vocações, em Weber (2004), e a A Redução Sociológica, de Guerreiro Ramos (1996). A análise crítica remetida a essas produções, interpreta a tensão das organizações institucionais, que extrapolam a condição do jogo e da disputa à organização das licenciaturas, na formação das universidades. Portanto, o conhecimento produzido, acaba recebendo severas influências, dessa "queda de braços" e das relações de poder interpostas entre o campo universitário e suas Licenciaturas.

IV. Orientações metodológicas e epistêmicas: esta seara de discussões é uma representação diferente ao meio, uma vez que, projeta-se como uma das poucas participações de expertises internacionais, apenas duas, Pereyra (2013), da Argentina e Lahire (2013), da França. Entretanto, a questão epistemológica da área continua sendo "Para que serve a Sociologia?". A propósito, se desenham sistematizações das possíveis acolhidas que podem ser apropriadas pelo subcampo, com a finalidade de reposicionar-se na luta acadêmica escolar de lugares, justificativas e 
legitimações do métier no subcampo da sociologia na educação básica.

Os Livros Coletâneas apresentam ainda uma variação no conjunto de suas vinculações de produção: a) locais, no formato de projetos institucionais dos cursos de Licenciatura (Laboratórios de Ensino e Pesquisa); b) interinstitucionais e interdisciplinares, no interior das universidades ou conglomerados a outras universidades ou regiões do país; balanços e estados da arte, a partir da participação de entidades e comissões científicas, associações e reunião das expertises da área, destacando a materialização dos debates a partir dos eventos da área, como é o caso do Encontro Nacional sobre o Ensino de Sociologia na Educação Básica (ENESEB).

Ainda com relação as agendas-temas dos Livros- Coletâneas, foram identificadas 29 (vinte e nove) instituições de ensino superior e de redes públicas de ensino na representatividade do debate, numa concentração dos estudos localizados no eixo Rio de Janeiro ${ }^{5}$ - Paraná6.

Pode-se perceber que a finalidade central dos Livros Coletâneas intenciona assegurar a fala, a democratização das ideias sociológicas e configurar a legislação educacional. Por esse aspecto, os projetos se materializaram em laboratórios de ensino. Assim, os cientistas sociais somam o que é de domínio intelectual às instâncias do ensino. Contudo, a base de conhecimento das Ciências Sociais se contrapõe à banalização de senso comum, que priva a função reflexiva, inerente às propostas de ensino, que são primeiramente sociológicas. Assim, a condição de "experienciar" projetos em laboratório, ou ainda, nas relações de ensino de uma sala de aula, está intrinsicamente ligada à atitude cognitiva predisposta à inovação - essa é a premissa que se percebe nos Livros Coletâneas.

Logo, as produções em coletâneas, abrem-se para a continuidade das conversas. O ponto forte de envolvimento da coletividade, da origem e da educação está nas próprias atividades enraizadas na atuação com a Licenciatura em Ciências Sociais. Coadunam uma intensa rotina de atividades, cujas diversidades ampliam a abordagem. Porém, note-se que, tomados pelas funções cotidianas, engavetam-se muitos projetos e criações simbólicas, preciosas ao campo.

Ressalta-se que, as redes de pesquisa e estudos também são um dado importante a ser problematizado, uma vez que, é importante inferir que o número de pesquisadores não é extenso, considerando os nomes que figuram com mais assiduidade ao campo. Os encontros ocorrem pela agenda de eventos, pela via das publicações de pesquisas, no formato de livros ou revistas, torná-los

\footnotetext{
${ }^{5}$ A Universidade Federal do Rio de Janeiro (UFRJ) lidera a lista de representação de capítulos de livros, figuram ainda a APERJ, UFFRJ, UFF, UENF, IFRJ, SEDUC/RJ, PUCRJ, Colégio Pedro II, UERJ, CEFET/RJ, Universidade Estácio de Sá.

${ }^{6}$ No Estado do Paraná listam no debate a Universidade Estadual de Londrina - UEL e a Universidade Federal do Paraná - UFPR.
} 
conhecidos entre si.

Porém, dada à abrangência de suas atividades, cujos cursos de Licenciatura, tomam intensamente suas rotinas, as práticas acontecem por projetos e ações locais interligadas -, é o caso da Universidade Estadual de Londrina, - que toma a dianteira dos exemplos, das produções, dos projetos, uma liderança prodigiosa, no interior das Licenciaturas em Ciências Sociais, percebidas, no esforço de reflexão, pela materialização das ideias e das experiências em livros, em duas vias: a) o laboratório de ensino em Ciências Sociais; a especialização do ensino de Sociologia; o mestrado em Ciências Sociais. O locus de origem e letramento científico e docente derivado de uma raiz de pertencimento, eminentemente, sociológicas (ERAS, 2014); b) assessoria, consultoria, acompanhamento, palestras, eventos, produções, estágio supervisionado, oficinas metodológicas, provenientes no seio da escola básica e pública de ensino, cujo eixo de conexão busca interagir e dinamizar os conhecimentos produzidos na escola e na universidade.

Além da rede conectada às ações institucionalizadas locais, nota-se no subcampo, um esforço de mobilizar, em obras coletâneas, análises de projeções nacionais, cujas posições e ações dos agentes, geram diferentes disposições do mesmo subcampo: levantar temas, gerar fundamentosteórico-sociológicos, preparar novos quadros e gerações de professores e especialistas, para renovar o círculo de ideias, aumentar a projeção do próprio subcampo, tornando-a uma possibilidade de trabalho e uma perspectiva de pesquisas.

Para tanto, pesquisas sobre esse novo momento, - por exemplo, no interior do contexto pibidiano, de suas dinâmicas, inscrição do habitus docente e do cientista social-professor -, conferem um dos novos temas. Não obstante, outros desdobramentos se renovam quando a perspectiva de ensino se torna mais visível e presente na formação do cientista social.

Entretanto, há algumas lacunas severas que se revelam nessa seara. Isto porque, apesar do retrato das ações e do aumento dessas mesmas produções, há o limite de exemplares, o baixo volume de livros editados e poucos deles não são produzidos numa versão que concerne à lógica da sociedade informacional. Porém, criticamente, é preciso encarar os desdobramentos de seus efeitos, num impacto, oposto, ao requerido, ou seja, que as obras possam de fato gerar democratização de conhecimento. Logo, não se tem todos os elementos para afirmar com segurança, se as obras coletâneas efetivamente, chegam com longo alcance e volume às escolas e ao ensino da Educação Básica. E, também não se tem uma dimensão exata, do modo, como estão circulando nas Ciências Sociais, ou mais especificamente, sobre as Licenciaturas.

Os materiais são divulgados e lançados nos eventos da área e nos projetos de ensino voltados às escolas e aos PIBID's. Mas uma nova pesquisa, ajudaria a mensurar com critérios de alcance mais sistêmicos esse momento vivido no Ensino de Sociologia (ERAS, 2014). Consta que 
mais uma vez, as esferas da tensão e da contradição instalam-se no arquétipo do subcampo. As obras são um registro de mudanças de modalidades de apresentação, dinâmica, circulação de ideias e estudos no campo. Isso pode ser afirmado ao se tomar a história de invisibilidade e insulamento acadêmico sobre o qual algumas obras apontavam. Tanto é verdade que, houve movimentos e mudanças no processo, inclusive, quando políticas públicas científicas, são movidas como recursos de reconstrução do conhecimento sociológico nas Ciências Sociais.

Nesse propósito, observa-se que, os autores dos livros usaram de uma honestidade acadêmica, ao assumirem, que sim, as obras precisam de uma melhor projeção, organicidade aos estudos, internacionalização, melhorias na construção teórica de abordagens, estabelecimento de parcerias, que veiculem, pesquisadores das Ciências Sociais "clássicos" aos projetos avaliadores e perspectivistas do ensino de Sociologia, ou mesmo das tarefas consideradas mais domésticas, versar sobre metodologias e didáticas de ensino, suas teorizações e transposições de ensino e, um aspecto, em estudo, a busca de um currículo mínimo comum, até agora, ainda não consensuado neste subcampo.

As obras são produzidas em quatro locus/processos de desenvolvimento: a) as obras são sínteses de eventos acadêmicos; b) as obras são sínteses de projetos desenvolvidos em laboratórios de ensino e pesquisa sobre o Ensino; c) as obras são resultados da avaliação crítica do subcampo; d) as obras são especificações temáticas do subcampo do Ensino de Sociologia. No conjunto de uma avaliação crítica quanto aos avanços que representam essas produções, temos: 1) a repercussão do trabalho desenvolvido em novos espaços e desenhos institucionais, especialmente localizados na formação de professores em Ciências Sociais; 2) a produção de conhecimento escolar que se coaduna com um letramento sociológico científico; 3) a presença dos Programas Institucionais de Bolsa de Iniciação à Docência em suas autorias; 4) a ênfase do lugar da experiência nas produções; 5) enfim, o processo de constituição das próprias obras em si, naquilo que permite fertilizar, condensar e desafiar o próprio debate (ERAS, 2014).

Já num olhar crítico lacunar, peca-se pelas ausências, sobretudo, a de aprofundamento em grande parcela de suas discussões: 1) quanto a outros processos de aprendizado interdisciplinares (neurociência, psicologia, pedagogia); 2) da reflexão sobre a ludicidade das práticas de ensino; 3) a incorporação de novas linguagens à esfera de reflexão sobre o ensino; 4) a baixa tiragem de livros coletâneas editados (300, 500, 1000 edições) e a não digitalização e, logo, dificuldades para a acessibilidade das obras; 5) a não uniformidade de representação regional/nacional e institucional, predominando produções localizadas no Sul e no Sudoeste do país.

Na escrita sociológica dos livros coletâneas se ressoa as vozes dos pensadores sobre a 
educação e o ensino de sociologia, transformadas em obras que reflitam a cientificidade dos saberes, a inovação pela prática de ensino e a transferência da luta de um pensamento sobre a escola, a formação de professores e a circulação dessas ideias entre os próprios pares das Ciências Sociais. Tal escrita é um registro de lutas e utopias, nas quais o campo do Ensino de Sociologia se reinventa, no jogo conjunto das forças sociais, contidas dentro e fora das Ciências Sociais, que pensa os processos de democracia do conhecimento e do seu alcance na formação de novos cientistas e professores e professoras de Sociologia/Ciências Sociais.

\section{Referências}

BRASIL. Legislação Brasileira sobre educação. Brasília: Câmara dos Deputados, edições câmara, 2009.

CARIDÁ, Ana Carolina Bordini Brabo. O currículo de Sociologia no Ensino Médio. In: SOUZA PONTES, Fernando. Sociologia: conhecimento e ensino. Florianópolis: Editoria em Debate, 2012, p. 37-64.

ERAS, Lígia Wilhelms. A produção de conhecimento recente sobre o Ensino de Sociologia/Ciências Sociais na Educação Básica no formato de livros coletâneas (2008-2013): sociologias e trajetórias. Tese de Doutorado. Programa de Pós-Graduação em Sociologia. Universidade Federal do Paraná, 2014.

ERAS, Lígia Wilhelms. Trajetórias, travessias e produtores: sociologias, conhecimentos e os autores dos livros coletâneas sobre o Ensino de Sociologia na Educação Básica. In: SILVA, Ileizi Luciana Fiorelli, SOUZA MARTINS, Heloísa Helena (orgs.). Dossiê Ensino de Sociologia. São Paulo. Revista Brasileira de Sociologia. Vol. 2, n 3, p. 259-288, 2014.

ERAS, Lígia. FEIJÓ, Fernanda. Por uma transposição didática das teorias das Ciências Sociais (Sociologia, Antropologia e Ciência Política): teorizações sobre as práticas de ensino em Ciências Sociais. In: Sociologia e Juventude no Ensino Médio: formação, PIBID e outras experiências. Fortaleza: Pontes, 2013, p. 87-99.

HANDFAS, Anita. O estado da arte do Ensino de Sociologia na Educação: um levantamento preliminar da produção acadêmica. Natal: Revista Inter-legere, nº 9, p. 386-400, 2011.

HANDFAS, Anita; MAÇAIRA, Júlia Polessa. O estado da arte da produção científica sobre o Ensino de Sociologia na Educação Básica. São Paulo: Revista Brasileira de Informação Bibliográfica em Ciências Sociais - BIB, nº 74, p. 45-61, 2012.

LAHIRE, Bernard. Viver e interpretar o mundo social: para que serve o Ensino de Sociologia? In: GONÇALVES, Danyelle Nilin (org). Sociologia e Juventude no Ensino Médio: formação, PIBID e outras experiências. Campinas: Pontes Editora, 2013, p. 15-30.

PEREYRA, Diego. A formação de professores de Sociologia na Argentina - desafios e experiências institucionais. In: GONÇALVES, Danyelle Nilin (org). Sociologia e Juventude no Ensino Médio: formação, PIBID e outras experiências. Campinas: Pontes Editora, 2013, p. 129-138. 
Guerreiro RAMOS, Guerreiro, Alberto. A redução sociológica. Rio de Janeiro: Editora da UFRJ, 1996.

WEBER, Max. Ciência e Política: duas vocações. Edição? São Paulo: Editora Cultrix, 2004.

\section{Livros coletâneas sobre o Ensino de Sociologia - 2008/2013 ${ }^{7}$}

CARVALHO, Cesar Augusto (org.). A Sociologia no Ensino Médio (org.) - Londrina: EDUEL, 2010.

FIGUEIRO, André Videira; OLIVEIRA, Luiz Fernandes; PINTO, Nalayane Mendonça. Sociologia na sala de aula: reflexões e experiências docentes no Estado do Rio de Janeiro. Rio de Janeiro: Imperial Novo Milênio, 2012.

GONÇALVES, Danyelle Nilin (org.). Sociologia e Juventude no Ensino Médio: formação, PIBID e outras experiências. Pontes Editores: Campinas, 2013.

HANDFAS, Anita. OLIVEIRA, Luiz Fernandes (orgs.). A Sociologia vai à escola (org.) - Rio de Janeiro: Quartet FAPERJ, 2009.

HANDFAS, Anita; MAÇAIRA, Júlia Polessa (orgs.). Dilemas e perspectivas da Sociologia na Educação Básica. Rio de Janeiro: E-papers, 2012.

LIMA, Angela Maria de Sousa; ARAÚJO, Angélica Lyra; FERREIRA, Jaqueline; MOTTA, Sílvia Conceição Longuin. Sugestões didáticas de Ensino de Sociologia. Londrina: UEL, 2012.

LIMA, Angela Maria Sousa, VITALIANO, Célia Regina, ALTIANO, Fabiane Cristina, MACHADO, Rosemeri Passos Baltazar. Inclusão: debates em diferentes contextos. Londrina: EDUEL, 2013.

LIMA, Angela Maria Sousa, ARAÚJO, Angélica Lyra; LIMA, Alexandre Jerônimo Correia;

FERREIRA, Adriana Fátima; CARVALHO, Cézar Augusto; SILVA, Ileizi Luciana Fiorelli; SCHEVIBISKI, Renata Schlumberger; SILVEIRA, Ricardo de Jesus. Práticas e Debates na formação de professores de Sociologia/Ciências Sociais. Londrina: EDUEL, 2013.

MEIRELLES, Mauro; RAIZER, Leandro; PEREIRA, Luiza Helena (org.). O ensino de sociologia no RS: repensando o lugar da sociologia (org.) - Porto Alegre: Evangraf/LAVIECS, 2013.

MORAES, Amaury César (org.). Coleção Explorando o Ensino. Sociologia. Volume 15. Ministério da Educação, Secretaria de Educação Básica, 2010.

OLIVEIRA, Dijaci David (org.). Sociologia e educação em direitos humanos (org.) - Goiânia: Fundação de Apoio à Pesquisa na UFG (FUNAPE), 2011.

OLIVEIRA, Luiz Fernandes, André Videira, Nalayane Pinto. Sociologia na sala de aula: reflexões e experiências docentes no Estado do Rio de Janeiro. Rio de Janeiro: Imperial Novo Milênio, 2012.

7 As obras aqui descritas são as que foram utilizadas para a análise temática e de conteúdos na tese de doutorado. 
OLIVEIRA, Luiz Fernandes (org.). Ensino de Sociologia: desafios teóricos e pedagógicos para a s Ciências Sociais. Seropédica, RJ: Editora d a UFRRJ, 2013.

RAMALHO, José Rodorval. SOUZA, Rozenval de Almeida (org.). Pibid: Memórias de iniciação à docência. Campina Grande: Editora da UFCG, 2013.

SILVA, Ileizi Luciana Fiorelli (org.) Cadernos de metodologias de ensino e pesquisa de sociologia: Lenpes laboratório de ensino, pesquisa e extensão de sociologia. (org.) - SETI-PR, 2009.

SOUSA, Fernando Ponte (org.). Sociologia conhecimento e ensino (org.) - Florianópolis: Editoria em Debate, 2012. 